\title{
EFICÁCIA DE ARMADILHAS E ATRATIVOS ALIMENTARES ALTERNATIVOS NA CAPTURA DE MOSCAS-DA-FRUTA EM POMAR DE GOIABA*
}

\author{
F.R. Azevedo, L.S. Gurgel, M.L.L. Santos, F.B. Silva, M.A.R. Moura, D.R. Nere \\ Universidade Federal do Ceará, Av. Tenente Raimundo Rocha, s/no, CEP 63040-360, Juazeiro do Norte, CE, \\ Brasil. E-mail: razevedo@ufc.br
}

\author{
RESUMO
}

\begin{abstract}
Este trabalho objetivou avaliar a eficácia de armadilhas e atrativos alimentares alternativos na captura de moscas-da-fruta (Diptera: Tephritidae). Os estudos foram realizados em um pomar de goiaba no Crato, CE, nos períodos de 6 de novembro a 18 de dezembro de 2009 (armadilhas) e 13 de janeiro a 24 de fevereiro de 2010 (atrativos). Utilizaram-se pote de margarina, frasco de vinagre, garrafa PET, frasco de álcool, garrafa de óleo vegetal, garrafa de detergente e garrafa de soro, para comparar com a armadilha McPhail, tendo como atrativo alimentar a proteína hidrolisada de milho. Empregaram-se caldo de cana-de-açúcar, fermento industrializado de pão, vinagre tinto de uva, suco de goiaba, açúcar mascavo, urina humana e açúcar cristal, para comparar com a proteína hidrolisada de milho, utilizando-se a armadilha McPhail. Os experimentos foram inteiramente casualizados, com avaliações semanais. A garrafa PET pode ser utilizada em substituição a McPhail na captura de moscas-das-frutas, com maiores capturas na primeira e segunda avaliação após a instalação das armadilhas. O suco de goiaba pode ser utilizado na captura de moscas-das-frutas em substituição a proteína hidrolisada de milho, enquanto que o fermento e o vinagre demonstraram-se ineficazes.
\end{abstract}

PALAVRAS-CHAVE: Monitoramento, moscas frugívoras, Psidium guajava.

\begin{abstract}
EFFICACY OF TRAPS AND FOOD LURES FOR FRUIT FLY CAPTURE IN A GUAVA ORCHARD. This work aimed to evaluate the efficacy of alternative traps and food lures in capturing fruit flies (Diptera: Tephritidae). This research was carried out in a guava orchard in Crato, state of Ceará, Brazil, from 6 November to 18 December 2009 (traps) and from 13 January to 24 February 2010 (food lures). To compare them with McPhail traps containing hydrolyzed corn protein as food lure, we utilized margarine containers, vinegar bottles, PET bottles, alcohol bottles, vegetable oil bottles, saline-solution bottles and detergent bottles. For purposes of food lure comparison, sugarcane juice, industrialized baker's yeast, red grape vinegar, guava juice, brown sugar, human urine and crystal sugar were used as alternatives to hydrolyzed corn protein, using the McPhail traps. The experiments were set up using a completely randomized design; evaluations occurred once a week. PET bottles may replace McPhail traps, with higher captures of fruit flies observed at the first and second evaluation after installation of traps. Guava juice may replace hydrolyzed corn protein to capture these pests, while industrialized baker's yeast and red grape vinegar were inefficient in fruit fly capture.
\end{abstract}

KEY WORDS: Monitoring, fruit flies, Psidium guajava.

\section{INTRODUÇÃO}

A região do Cariri, localizada noSul do Estado do Ceará, tem ganhado evidência pelo grande avançona exploração da fruticultura. A irrigação e as condições de solo e clima têm favorecido esse aumento da fruticultura. Essa região possui uma área de 45 ha de goiabeiras, sendo distribuída pelos municípios de Crato, com 15 ha, Barbalha 16, Santana do Cariri 2 ha e Missão Velha 12 ha. Esse cenário vem mudando gradativamente graças aos incentivos de crédito direcionado para a agricultura familiar (INSTITUTO Agropolos..., 2012). No entanto, com a ampliação das áreas cultivadas, há o aumento da incidência de pragas, como as moscas-das-frutas.

A goiaba (Psidium guajava L.) é uma das frutas mais afetadas pelas mosca-da-fruta no Brasil. Anastrepha spp. e Ceratitis capitata (Wied.) são as

*Pesquisa financiada pelo Banco do Nordeste - FUNDECE/ETENE. 
principais pragas da goiaba (MANICA et al., 2000). Dez espécies de Anastrepha, além de C. capitata, estão associadas à goiaba no País (ZucCHI, 2001). No Cariri, a incidência dessas moscas é um sério problema durante todo ano na região, acarretando aumentos nos custos de produção, em razão das frequentes aplicações de inseticidas e perdas na produção.

De acordo com AzEVEDo et al. (2010), estão associadas à goiabeira nessa região, as espécies Anastrepha zenildae Zucchi, A. sororcula Zucchi, A. fraterculus (Wied.), A.obliqua (Macquart) e C. capitata. Além disso, os impactos negativos sobre a entomofauna benéfica com aplicação dos inseticidas de amplo espectro são significativamente ampliados, pois afetam negativamente as cadeias alimentares e são prejudiciais à saúde humana e ao agroecossistema da goiabeira.

Elas são pragas de importância quarentenária por causarem danos diretos aos frutos de goiaba e por apresentarem grande capacidade de adaptação a diferentes regiões. As larvas alimentam-se da polpa dos frutos, tornando-os impróprios para o consumo ou para a industrialização, causando sérios prejuízos (ARAujo; ZucChI, 2003).

A possibilidade de cultivo da goiaba sem o uso de inseticidas químicos, associada às exigências por parte dos consumidores, tem motivado a conversão de pequenas áreas produtoras para o sistema agroecológico sem redução na produtividade, porém, poucos trabalhos têm sido realizados, visando a identificar eanalisar a eficiência de táticas disponíveis para o manejo agroecológico de moscas-da-fruta. Essas táticas geralmente são utilizadas de forma empírica, baseada em observações isoladas e, muitas vezes, sem comprovação científica.

Armadilhas com atrativos são meios importantes e decisivos para maior acuidade na detecção, monitoramento e controle dessas pragas. Atualmente, há um crescente esforço para a melhoria e a obtenção de materiais e métodos mais eficientes para estes fins.

Vários trabalhos têm sido realizados utilizando armadilhaseatrativos paraacaptura demoscas-da-frutana cultura da goiaba (Lemoset al., 2002; AluJA; PIÑERO, 2004; CAMARGO; GuerreIro, 2007; Costa et al., 2008) eem outras fruteiras (MonTES; RAGA, 2006). Entretanto, é preciso realizar mais estudos buscando alternativas locais para um manejo ecologicamente correto e economicamente viável dessa praga para evitar ônus adicionais para os pequenos produtores, bem como proteger o meio ambiente e conservar os inimigos naturais nativos presentes no agroecosistema da goiabeira.

Devido à grande variabilidade de informações referentes aos tipos de armadilhas e aos atrativos alimentares disponíveis, este trabalho teve como objetivo verificar a eficácia de armadilhas alternativas ao modelo McPhail e de atrativos alimentares alternativos a proteína hidrolisada de milho na cap- tura de moscas-da-fruta em um pomar de pequeno produtor rural.

\section{MATERIAL E MÉTODOS}

Eficácia de armadilhas alternativas na captura de moscas-das-frutas

A pesquisa foiconduzida em um pomar comercial de goiaba ( $P$. guajava) com dez anos de idade, com frutos da variedade Paluma, durante o período de 6 de novembro a 18 de dezembro de 2009 (fase de frutificação), localizado no Município de Crato, Ceará, (Latitude $7^{\circ} 13^{\prime} 25,1^{\prime \prime}$ Se Longitude 39 $23^{\prime} 29,63^{\prime \prime} \mathrm{O}$ ). As goiabeiras foram plantadas no espaçamento de 6,0 x 5,0 m totalizando 0,5 ha de área efetiva de monitoramento. Nessa área de cultivo foram adotadas todas as práticas culturais rotineiras, sem haver, no entanto, aplicações de inseticidas químicos.

As armadilhas alternativas constituídas por recipientes plásticos (potes de margarina de $1.000 \mathrm{~g}$ brancos, frascos de vinagre $750 \mathrm{~mL}$ transparentes, garrafas PET de $2 \mathrm{~L}$ transparentes, frascos de álcool $1 \mathrm{~L}$ transparentes, garrafas de óleo $1 \mathrm{~L}$ transparentes, garrafas de detergentes $500 \mathrm{~mL}$ transparentes e garrafas de soro $500 \mathrm{~mL}$ transparentes) foram comparadas com a eficácia da armadilha padrão tipo McPhail usando como atrativo alimentar a proteína hidrolisada de milho a $5 \%$.

Cada armadilha alternativa apresentava oito furos de $0,5 \mathrm{~cm}$, localizados na parte mediana nas garrafas PET, frascos de álcool e garrafas de óleo e no terço superior nos potes de margarina, frascos de vinagre, garrafas de detergentes e garrafas de soro. Os furos eram distanciados $3 \mathrm{~cm}$ entre si e cada planta envolvida no experimento recebia uma armadilha.

As armadilhas foram instaladas em fileiras alternadas, a uma altura de $1,80 \mathrm{~m}$ do solo, nos ramos externos das plantas distanciadas, no mínimo, $20 \mathrm{~m}$ entre si. Cada armadilha foi abastecida com $400 \mathrm{~mL}$ do atrativo alimentar, sendo avaliada semanalmente, pois, a partir de sete dias, a solução atrativa tende a diminuir sua eficiência quanto à atratividade das moscas e, portanto, diminuindo a captura desses insetos (NASCIMENTO et al., 2000). Em seguida, substituía-se o atrativo e as armadilhas eram rotacionadas entre si no sentido horário, ou seja, da direita para a esquerda dentro da copa da planta.

Eficácia de atrativos alimentares alternativos na captura de moscas-da-fruta

Visando a comparar atrativos alimentares facilmente encontradas no Cariri, alternativos à proteína hidrolisada de milho, para capturar moscas-da-fruta, foi conduzida uma pesquisa no mesmo pomar comercial de goiaba da pesquisa anterior, no período 
de 13 de janeiro a 24 de fevereiro de 2010 (fase de maturação e colheita dos frutos), não havendo também aplicações de inseticidas químicos.

Os atrativos avaliados foram diluídos em água na seguinte proporção: proteína hidrolisada de milho (Bioanastrepha ${ }^{\circledR}$ ) a 5\% (testemunha referência), caldo de cana-de-açúcar a 50\%, fermento biológico Mauri ${ }^{\circledR}$, proveniente de Pederneiras, SP, a 10\%, vinagre tinto de uva a $30 \%$, suco de goiaba a $30 \%+10 \%$ de açúcar cristal, açúcar mascavo a $10 \%$, urina humana a $100 \%$ e açúcar cristal a $20 \%$. Todos os atrativos foram preparados no dia anterior ao da aplicação e foram colocadosnas armadilhas McPhailutilizando a mesma metodologia da pesquisa anterior. A urina humana foi coletada um dia antes da aplicação, proveniente deum doador com 40 anos de idade, utilizando-se um funil de plástico e, seguida, armazenada em uma garrafa PET de $2 \mathrm{~L}$ transparente em condições ambiente. $\mathrm{O}$ mesmo foi feito para os outros atrativos alimentares, colocando-os tambémnas mesmas condições da urina.

Os experimentos (armadilhas e atrativos) foram conduzidos no delineamento inteiramente casualizado, estabelecendo-se quatro repetições para cada tratamento, totalizando 32 parcelas, representada por cada planta em cada experimento instalado.

Os insetos de ambos os experimentos foram coletados com o auxílio de uma peneira plástica de malha fina e um pincel, acondicionados em frascos plásticos de $100 \mathrm{~mL}$ contendo álcool a $70 \%$ e, em seguida, levados ao Laboratório de Entomologia do Campus Cariri para triagem, quantificação e identificação. $\mathrm{O}$ número de insetos capturados foi apresentado como número médio de adultos/ armadilha/semana.

Os dados obtidos foram submetidos à análise estatística, comparando-se as médias pelo teste Fisher'S LSD a 5\% de probabilidade.

\section{RESULTADOS E DISCUSSÃO}

No experimento que visou comparar a armadilha McPhail com as confeccionadas a partir de recipientes plásticos utilizando a proteína hidrolisada de milho a 5\% como atrativo alimentar, constatou-se que nenhuma armadilha testada diferiu significativamente da armadilha McPhail na captura de fêmeas de Anastrepha spp. (Tabela 1).

Observou-se, no entanto, maior número defêmeas coletadas no frasco de vinagre em comparação à garrafa de detergente e ao pote de margarina (o frasco de vinagre não diferiu da Armadilha McPhail) (Tabela 1).

Houve menor número de machos coletados no pote de margarina e na garrafa de óleo em relação à testemunha, mas não houve diferenças significativas em relação às demais armadilhas testadas (Tabela 1).
Levando-se em consideração o total de adultos capturados (fêmeas + machos), nas seis semanas de avaliação, para cada armadilha, observou-se maior captura na garrafa PET, com um total de 432 adultos, seguida do frasco de vinagre com 305 . As demais armadilhas obtiveram valores abaixo do encontrado na testemunha. BARros et al. (1991) comentaram que quando a armadilha McPhail é comparada com modelos alternativos, a maioria destas é menos efetiva na captura de moscas desse gênero. Fato esse não observado neste trabalho que verificou capturas até maiores de Anastrepha spp. em duas armadilhas do que no modelo McPhail com garrafas plásticas adaptadas, como no caso da garrafa PET e o frasco de vinagre, que capturaram mais adultos do que a testemunha, que capturou 267 adultos.

Corroborando com essa constatação, LORENZATO (1984) verificou que o frasco caça-moscas modelo garrafa plástica é mais prático para o monitoramento dos tefritídeos que o modelo McPhail, por ser de fácil aquisição, adequação, reposição, uso específico em pomares e oferecer perspectivas promissoras para uso extensivo no meio rural.

O número total de adultos capturados em todas as armadilhas, nas seissemanas decoletas, foi de1.622(Tabela1), sendoquea proporçãofoi deaproximadamente duas fêmeas capturadas para cada macho. Pelo grande número de moscas capturadas e retiradas do pomar, principalmente as fêmeas, percebe-se a importância dessas armadilhas como uma tática agroecológica de reduzir a população da praga sem o uso de inseticidas químicos e, portanto, os seus danos econômicos na goiabeira, obtendo-se frutos sem resíduos químicos.

Ocusto tambémé outro fator importante a serconsiderado quando se trabalha em programas de monitoramento e/ou controle de pragas, especialmente quando envolve produtores com baixa renda, pois as armadilhas confeccionadas com material alternativo pode ser uma opção viável para avaliar a população da praga visando racionalizar o controle, a exemplo doque foi observado por BRESSAN; TeLES (1991) eSALLES (1999) que também avaliaram Anastrepha spp. Essas armadilhas alternativas, por serem de material barato, de fácil disponibilidade, reutilizável, desinteressante para roubo e de fácil confecção pelo usuário, podem ser utilizadas pelos pequenos e médios produtores no controle das moscas-da-fruta, sem trazer ônus adicionais na produção da goiabeira.

Durante o período em que as armadilhas ficaram expostas no pomar, observou-se que nos dias 13/11/2009 e 20/11/2009, onde foram feitas a primeira e segunda avaliação após a instalação, que correspondeu aos 7 e 14 dias de permanência das armadilhas no campo, a garrafa PET capturou uma maior população média de 36,75 e 32,75 adultos de Anastrepha spp. (fêmeas e machos) e 147 e 131 em valores totais, respectivamente, reduzindo para 16,25 
adultos, no dia 27/11/2009 (Tabela 2), não diferindo estatisticamente da armadilha McPhail, frasco de vinagre, garrafa de detergente e frasco de soro. Na primeira avaliação ocorreu uma precipitação de 26,2 mm (Instituto..., 2012). Portanto, esse fator climático afetou indiretamente a flutuação populacional das moscas-da-fruta, por meio da oferta de frutos hospedeiros para o desenvolvimento das larvas das moscas.

Aguiar-Menezes et al. (2006) também verificaram no período de 7 e 15 dias de coleta, que as armadilhas PET capturaram mais moscas-da-fruta (76 e 142 adultos, respectivamente) do que as armadilhas McPhail, valores estes próximos aos encontrados na presente pesquisa.

Seguido da garrafa PET, observou-se que o frasco de vinagre coletou, nesses mesmos períodos, 20 e 17,75 adultos, respectivamente, valores estes acima da testemunha. Já a armadilha McPhail capturou uma população abaixo de 15 indivíduos nesses períodos mencionados. Esse mesmo comportamento de maior captura também foi observado na garrafa de detergente no dia 13/11/2009 e no frasco de soro, nos dias 13/11/2009 e 20/11/2009.

No entanto, o pote de margarina, a garrafa de óleo e o frasco de álcool demonstraram capturas diferentes a essas (Tabela 2).

Portanto, verificou-se na presente pesquisa que, na maioria das armadilhas testadas, as maiores capturas de Anastrepha spp. ocorreram na primeira e segunda avaliação após a instalação das armadilhas no pomar, diminuindo a população progressivamente até a última avaliação que foi realizada no dia 18 de dezembro de 2009 (Tabela 2). Nessa data, como não havia mais chuvas, a temperatura aumentou para $28^{\circ} \mathrm{C}$ e a umidade relativa diminuiu para $55 \%$.

Tabela 1 - Número médio total de fêmeas e machos de Anastrepha spp. capturados em armadilhas alternativas ao modelo McPhail no período de novembro a dezembro de 2009, em um pomar de goiaba no Município do Crato, CE.

\begin{tabular}{lcrr}
\hline Tratamentos & Fêmeas & Machos & Total por tratamento \\
\hline Armadilha McPhail & $39,50^{1,2} \mathrm{ab}$ & $28,00 \mathrm{a}$ & 267 \\
Pote de margarina & $12,25 \mathrm{~b}$ & $8,25 \mathrm{ab}$ & 82 \\
Frasco de vinagre & $54,25 \mathrm{a}$ & $22,00 \mathrm{ab}$ & 305 \\
Garrafa PET & $63,50 \mathrm{ab}$ & $44,50 \mathrm{ab}$ & 432 \\
Frasco de álcool & $21,75 \mathrm{ab}$ & $14,25 \mathrm{ab}$ & 144 \\
Garrafa de óleo & $23,50 \mathrm{ab}$ & $9,50 \mathrm{ab}$ & 122 \\
Garrafa de detergente & $18,25 \mathrm{~b}$ & $10,75 \mathrm{~b}$ & 114 \\
Garrafa de soro & $25,75 \mathrm{ab}$ & $13,25 \mathrm{ab}$ & 156 \\
\hline C.V. $(\%)$ & 31,34 & 36,03 & 150 \\
\hline Total por sexo & 258 & & 1.622 \\
\hline Total Geral & & & \\
\hline
\end{tabular}

${ }^{1}$ Dados transformados em $\log \mathrm{x}$.

${ }^{2}$ Médias seguidas de mesma letra na coluna não diferem significativamente entre si pelo teste de Fisher's LSD a 5\% de probabilidade.

Tabela 2 - Número médio de adultos de Anastrepha spp. capturados em armadilhas alternativas ao modelo McPhail nas seis avaliações de campo em um pomar de goiaba no Município do Crato, CE.

\begin{tabular}{|c|c|c|c|c|c|c|}
\hline \multirow{2}{*}{ Tratamentos } & \multicolumn{6}{|c|}{ Avaliações } \\
\hline & $1^{\mathrm{a}}(13 / 11 / 20092$ & $(20 / 11 / 2009)$ & $3^{a}(27 / 11 / 2009)$ & $4^{\mathrm{a}}(4 / 12 / 2009)$ & $5^{\mathrm{a}}(11 / 12 / 200$ & $18 / 12 / 2009)$ \\
\hline Armadilha McPhail & $13,75^{1,2} \mathrm{abc}$ & $11,75 \mathrm{bc}$ & $11,5 \mathrm{ab}$ & $3,5 \mathrm{bc}$ & $15,25 \mathrm{a}$ & $11,00 \mathrm{a}$ \\
\hline Pote de margarina & $5,00 \mathrm{bc}$ & $3,75 \mathrm{c}$ & $3,75 c$ & $4,25 \mathrm{abc}$ & $3,00 \mathrm{~cd}$ & $1,00 \mathrm{c}$ \\
\hline Frasco de vinagre & $20,00 \mathrm{ab}$ & $17,75 \mathrm{ab}$ & $8,25 \mathrm{abc}$ & $6,75 \mathrm{ab}$ & 15,75 a & $7,75 \mathrm{a}$ \\
\hline Garrafa PET & $36,75 \mathrm{a}$ & $32,75 \mathrm{a}$ & $16,25 \mathrm{a}$ & $6,00 \mathrm{ab}$ & $9,75 \mathrm{ab}$ & $6,5 \mathrm{ab}$ \\
\hline Frasco de álcool & $8,75 \mathrm{bc}$ & $4,5 \mathrm{bc}$ & $8,25 a b c$ & $6,75 \mathrm{ab}$ & $6,5 b c$ & $1,25 \mathrm{c}$ \\
\hline Garrafa de óleo & $2,75 \mathrm{c}$ & $6,75 \mathrm{bc}$ & $9,25 \mathrm{abc}$ & $7,5 \mathrm{a}$ & $3,75 \mathrm{~cd}$ & $3,00 \mathrm{bc}$ \\
\hline Garrafadedetergente & $14,25 \mathrm{abc}$ & $4,5 \mathrm{bc}$ & 4,75 bc & $2,5 \mathrm{c}$ & $1,5 \mathrm{~d}$ & $1,50 \mathrm{c}$ \\
\hline Frasco de soro & $14,25 \mathrm{abc}$ & $10,25 b c$ & $7,5 \mathrm{abc}$ & $3,5 \mathrm{bc}$ & $2,75 \mathrm{~cd}$ & $1,00 \mathrm{c}$ \\
\hline Total & 115,5 & 92 & 69,5 & 40,75 & 58,25 & 33 \\
\hline C.V. & 23,89 & 21,56 & 14,58 & 10,65 & 14,45 & 13,51 \\
\hline
\end{tabular}

${ }^{1}$ Dados transformados em $\sqrt{ } \mathrm{x}+1$

${ }^{2}$ Médias seguidas de mesma letra na coluna não diferem significativamente entre si pelo teste de Tukey a 5\% de probabilidade. 
À medida que houve diminuição gradativa na precipitação, ocorreu uma diminuição também gradativa no número de moscas coletadas (Tabela 2). Diante dos resultados obtidos, pode-se sugerir que a ocorrência desses tefritídeos para as condições do Crato encontra-se, em parte, relacionada à precipitação. AzEvedo et al. (2010) informaram que o período de maior incidência de moscas-da-fruta em pomares de goiaba no Cariri é o chuvoso e com temperaturas amenas.

Resultados semelhantes foram obtidos por ARAUJO; ZuCCHI (2003), queconstataram uma fortecorrelação negativa entre a temperatura e a infestação de moscas-da-fruta em pomar de goiabas em Mossoró, tendo verificado que nos meses onde a temperatura foi superior a $28^{\circ} \mathrm{C}$ não houve infestação de moscas nos frutos e os índices de captura nas armadilhas foram insignificantes.

De acordo com Garcia et al. (2003), o efeito da umidade relativa do ar sobre a biologia e comportamento das moscas-da-fruta ainda não está definido, porém, acredita-se que esta variável climática tenha algum tipo de influência sobre os adultos.

Essa maior predominância dos picos populacionais das moscas nas primeiras avaliações deveu-se também a maior disponibilidade de frutos de goiaba nessaépoca ea redução da população provavelmente ocorreu devido à redução da disponibilidade desses frutos que foram colhidos ao longo das outras avaliações no pomar.

A captura de $C$. capitata na maioria das armadilhas testadas foi muito baixa, não chegando sequer a atingir 10 adultos nos diferentes períodos de avaliação (Tabela 3). Somente a garrafa PET na primeira avaliação realizada no dia 13 de novembro de 2009 capturou em média 12 indivíduos. Nesse período, todas as armadilhas chegaram a capturar somente
18 moscas no total. Em levantamentos realizados por meio de armadilhas McPhail em seis regiões frutíferas do interior do Estado do Ceará, SAlEs; GONÇALVES (2000) evidenciaram a ocorrência de $C$. capitata apenas nas culturas do cafeeiro e da tangerineira. Corroborando com essa informação, AzEVEDO et al. (2010) detectaram na região do Cariri um baixo índice de constância para essa espécie, indicando que a sua ocorrência no pomar do Crato é acessória, provavelmente pela preferência por outras plantas hospedeiras na vegetação adjacente, já que existiam outros frutos hospedeiros comolaranjas. Na presente pesquisa, algumas armadilhas PET localizaram-se nas margens do pomar, o que possivelmente capturou moscas migrantes de áreas adjacentes que cultivavam laranjas e tangerinas.

$\mathrm{Na}$ pesquisa que visou a comparar a proteína hidrolisada de milho com atrativos alimentares alternativos, observou-se que o suco de goiaba capturou a maior quantidade de fêmeas $(190,75)$ e machos $(142)$ de Anastrepha spp. (Tabela 4), quando comparado com os demais atrativos e este não diferiu estatisticamente da testemunha referência com $(302,25)$ e $(145,25)$, respectivamente, demonstrando que este atrativo alimentar poderá ser utilizado na captura dessas pragas em substituição à proteína hidrolisada de milho em pequeno pomar. Confirmando essa afirmativa, em termos totais, o suco de goiaba capturou 1.331 adultos contra 1.790 capturados na proteína hidrolisada de milho, ou seja, bem próximos.

Em termos percentuais, CAMARGo; Guerreiro (2007) constataram em um pomar comercial de goiaba no Município de Garça, em São Paulo, que o suco de laranja e o melaço de cana coletaram $30,1 \%$ e $28,7 \%$, respectivamente, enquanto que o suco de goiaba coletou $22 \%$ e a proteína hidrolisada $19,7 \%$ do total.

Tabela 3 - Número médio de adultos de Ceratitis capitata capturados em armadilhas alternativas ao modelo McPhail nas seis avaliações de campo em um pomar de goiaba no Município do Crato, CE.

\begin{tabular}{|c|c|c|c|c|c|c|}
\hline \multirow{2}{*}{ Tratamentos } & \multicolumn{6}{|c|}{ Avaliações } \\
\hline & $1^{a}(13 / 11 / 2009)$ & $2^{a}(20 / 11 / 2009)$ & $3^{\mathrm{a}}(27 / 11 / 2009)$ & $4^{\mathrm{a}}(4 / 12 / 2009) 5$ & $5^{\mathrm{a}}(11 / 12 / 2009)$ & $6^{a}(18 / 12 / 2009)$ \\
\hline Armadilha McPhail & $1,25^{1,2} \mathrm{bc}$ & $1,00 \mathrm{~ns}$ & $0,50 \mathrm{~b}$ & $0,25 \mathrm{~b}$ & $0,25 \mathrm{~ns}$ & $1,50 \mathrm{a}$ \\
\hline Pote de margarina & $1,50 \mathrm{bc}$ & $0,50 \mathrm{~ns}$ & $0,75 \mathrm{ab}$ & $0,00 \mathrm{~b}$ & $0,00 \mathrm{~ns}$ & $0,25 b$ \\
\hline Frasco de vinagre & $1,00 \mathrm{bc}$ & $1,25 \mathrm{~ns}$ & $0,25 \mathrm{~b}$ & $0,00 \mathrm{~b}$ & $0,25 \mathrm{~ns}$ & $0,75 \mathrm{ab}$ \\
\hline Garrafa PET & $12,00 \mathrm{a}$ & $1,00 \mathrm{~ns}$ & $2,00 \mathrm{a}$ & $1,25 \mathrm{a}$ & $0,00 \mathrm{~ns}$ & $0,50 \mathrm{ab}$ \\
\hline Frasco de álcool & $0,00 \mathrm{~d}$ & $0,50 \mathrm{~ns}$ & $0,75 \mathrm{ab}$ & $0,00 \mathrm{~b}$ & $0,00 \mathrm{~ns}$ & $0,50 \mathrm{ab}$ \\
\hline Garrafa de óleo & $0,00 \mathrm{~d}$ & $0,25 \mathrm{~ns}$ & $0,00 \mathrm{~b}$ & $0,00 \mathrm{~b}$ & $0,00 \mathrm{~ns}$ & $0,00 \mathrm{~b}$ \\
\hline Garrafa de detergente & $1,75 \mathrm{~b}$ & $0,75 \mathrm{~ns}$ & $0,00 \mathrm{~b}$ & $0,25 b$ & $0,50 \mathrm{~ns}$ & $0,25 b$ \\
\hline Frasco de soro & $0,50 \mathrm{~cd}$ & $0,75 \mathrm{~ns}$ & $0,00 \mathrm{~b}$ & $0,25 \mathrm{~b}$ & $0,00 \mathrm{~ns}$ & $0,00 \mathrm{~b}$ \\
\hline Total & 18 & 5 & 4 & 2 & 1 & 4 \\
\hline C.V. & 14,88 & 23,19 & 21,98 & 22,36 & 25,60 & 23,60 \\
\hline
\end{tabular}

${ }^{1}$ Dados transformados em $\sqrt{ } \mathrm{x}+1$.

${ }^{2}$ Médias seguidas de mesma letra na coluna não diferem significativamente entre si pelo teste de Tukey a 5\% de probabilidade.

ns: Não significativo. 
O açúcar mascavo, apesar de não diferir estatisticamente, teve uma tendência de maior captura, depois do suco de goiaba, obtendo-se nesse atrativo, 52,50 fêmeas e 36,50 machos (Tabela 4) e isso é observado quando se leva em conta o total de moscas capturadas que foi de 356 adultos. Seguido desse atrativo, o açúcar cristal capturou em média 53,50 fêmeas e 19,75 machos, totalizando 293 adultos. Portanto, os atrativos à base de açúcares também demonstram uma boa eficácia na captura dessas pragas.

Já o vinagre de vinho tinto foi o menos eficiente tanto para fêmeas $(3,50)$ quanto para machos $(3,50)$, embora não tenha havido diferenças significativas entre os outros atrativos testados (Tabela 4), pois, considerando-se o total de adultos capturados, observou-se uma captura de apenas 28 adultos. $\mathrm{O}$ fermento industrializado de pão, que simula o efeito da tórula, capturou 13,25 fêmeas e 11,25 machos, obtendo-se um total de 98 adultos, valor este próximo do caldo de cana, que se assemelha ao melaço, que foi de 111 adultos, tendo capturado em média 17,25 fêmeas e 10,50 machos.

Em pomar de goiaba na Costa Rica, HedstRÖm; JIRÓN (1985) observaram que a tórula atraiu 8,4 vezes mais os adultos de Anastrepha spp. que o melaço de cana. Já SALLES (1999), avaliando o efeito do envelhecimento e decomposição do fermento de pão a $20 \%$, como atrativo para captura de $A$. fraterculus, concluiu que estes são fatores positivos e estão diretamente relacionados ao aumento do número de moscas capturadas. Na presente pesquisa, isso não ocorreu, pois o fermento ao decompor atraiu uma grande quantidade de moscas Calliphoridae e Sarcophagidae, ao invés de Tephritidae. Essa maior captura dessas moscas provavelmente ocorreu devido ao cheiro desagradável que o fermento emitiu ao longo dos sete dias em campo. Esse atrativo também foi o mais trabalhoso para repor, pois os resíduos do fermento ficavam retidos nas paredes das armadilhas, sendo necessária uma boa lavagem com uma escova antes de recolocar o atrativo.

Já a urina humana capturou em média 23,25 fêmeas e 11,00 machos (Tabela 4). A amônia presente na urina demonstra um importante papel na atração dos tefritídeos (HeAth et al., 1995) e alguns sais de amônia, como acetato de amônia ou carbonato, também atraem adultos de $A$. suspensa (Loew) e A. ludens (Loew) (Thomas et al., 2001). Em um estudo realizado em condições de laboratório com adultos de A. ludens, A. obliqua, A. serpentina (Wied.) e A. striata Schiner, PIÑERo et al. (2002) constataram que as respostas das moscas à urina humana depende do histórico alimentar, da idade e maturidade sexual do doador. As espécies de Anastrepha também respondem de formas diferentes a esses compostos nitrogenados presentes na urina humana (PIÑERO et al., 2003). Na presente pesquisa, a urina utilizada nas armadilhas foi proveniente de um doador com alimentação irregular, com quarenta anos de idade e, portanto, maduro sexualmente, motivo pelo qual acreditamos que influenciou na redução da captura das moscas, pois, em um estudo realizado em um pequeno pomar de goiaba, Aluja; PIÑERo (2004) constataram que as armadilhas iscadas com urina humana a $50 \%$ capturaram mais espécies de $A$. fraterculus, A. obliqua e A. serpentina do que as armadilhas McPhail. Portanto, a urina humana também representa uma alternativa viável de baixa tecnologia para pequenos produtores de baixa renda ou de subsistência em áreas rurais.

Tabela 4 - Número médio total de fêmeas e machos de Anastrepha spp. capturados em atrativos alimentares alternativos à proteína hidrolisada de milho, no período de janeiro a fevereiro de 2010, em um pomar de goiaba no Município do Crato, CE.

\begin{tabular}{lccc}
\hline Tratamentos & Fêmea & Macho & Total por tratamento \\
\hline Proteína hidrolisada de milho & $302,25^{1,2} \mathrm{a}$ & $145,25 \mathrm{a}$ & 1790 \\
Caldo de cana-de-açúcar & $17,25 \mathrm{~b}$ & $10,50 \mathrm{~b}$ & 111 \\
Fermento industrializado de pão & $13,25 \mathrm{~b}$ & $11,25 \mathrm{~b}$ & 98 \\
Vinagre tinto de uva & $3,50 \mathrm{~b}$ & $3,50 \mathrm{~b}$ & 28 \\
Suco de goiaba & $190,75 \mathrm{a}$ & $142,00 \mathrm{a}$ & 1331 \\
Açúcar mascavo & $52,50 \mathrm{~b}$ & $36,50 \mathrm{~b}$ & 356 \\
Urina humana & $23,25 \mathrm{~b}$ & $11,00 \mathrm{~b}$ & 137 \\
Açúcar cristal & $53,50 \mathrm{~b}$ & $19,75 \mathrm{~b}$ & 293 \\
\hline C.V. $\%$ ) & 6,76 & 4,90 & 380 \\
\hline Total por sexo & 656 & & 4.144 \\
\hline Total Geral & &
\end{tabular}

${ }^{1}$ Dados transformados em $\log \mathrm{x}$.

${ }^{2}$ Médias seguidas de mesma letra na coluna não diferem significativamente entre si pelo teste de Fisher's LSD a 5\% de probabilidade. 
Com relação aos períodos de avaliação dos atrativos alimentares presentes nas armadilhas no campo, percebeu-se que a armadilha com proteína hidrolisada de milho capturou uma quantidade maior de moscas na quinta avaliação realizada no dia 16/2/2010 e na última, no dia 24/02/2010, capturando-se nas armadilhas em média 122,75 e 134,5 adultos, respectivamente (Tabela 5). Nessa última data houve uma precipitação de $48,5 \mathrm{~mm}$ de chuva no Crato (INSTITUTO..., 2012). Fatores abióticos, como a precipitação pluvial, influenciam fortemente os demais componentes do clima, como a temperatura e a umidade relativa. Neste estudo, constatouse que a precipitação pluvial provocou a redução na temperatura que baixou para $25^{\circ} \mathrm{C}$ e aumentou a umidade relativa para $78 \%$, proporcionando as condições favoráveis para o desenvolvimento das moscas.

Já o suco de goiaba capturou maior quantidade na segunda avaliação do dia $27 / 1 / 2010$, obtendo-se 79,25 adultos. Nessa data a precipitação foi baixa com apenas $4,2 \mathrm{~mm}$ de chuva, que promoveu aumento da temperatura para $27^{\circ} \mathrm{C}$ e redução da umidade relativa para 74\% (INSTITUTO..., 2012). Provavelmente nessas condições o suco de goiaba é mais efetivo na atração das moscas.

A maior captura com o açúcar cristal foi na terceira avaliação, com 23 adultos, não ocorrendo chuvas nessa data e baixa umidade relativa (64\%) com temperatura de $27^{\circ} \mathrm{C}$ (Instituto..., 2012), enquanto que o açúcar mascavo alcançou maior pico na segunda, com 34 adultos. Esse atrativo e o suco de goiaba certamente precisam de alta temperatura e baixa umidade relativa, provavelmente para não haver alterações na composição química e/ ou física dos ingredientes que compõem o atrativo.
A urina humana aumentou gradativamente a captura até a quinta avaliação do dia 16/2/2010, obtendo-se uma população média de 13 adultos, baixando a seguir, na última avaliação, para 8,25 no dia 24/2/2010. A urina humana é uma fonte de amônia (PIÑERo et al., 2003) e por isso é considerada viável como atraente de moscas-da-fruta em pomares comerciais de frutas, porém, sua eficiência tem sido variável nos diferentes trabalhos realizados. $\mathrm{Na}$ quinta avaliação a temperatura estava em torno de $27^{\circ} \mathrm{C}$ e umidade relativa de $71 \%$ (INSTITUTO..., 2012). Em condições ambientee a temperaturas elevadas, há uma evaporação daágua que reduz ovolume da urina e aumenta a concentração de amônia (ZANCHETA, 2007). Na presente pesquisa, essas condições foram encontradas, promovendo assim maior captura das moscas devido a maior concentração de amônia presente na urina.

Ocaldo de cana capturou um número semelhante de moscas nos dias 27/1/2010 e 16/2/2010, datas estas com temperaturas elevadas e dias levemente secos, com $27^{\circ} \mathrm{C}$ de temperatura em ambos os dias e 74 e $71 \%$ de umidade relativa, respectivamente (INSTITUTO..., 2012)

O fermento de pão foi mais eficiente na terceira avaliação, com temperatura de $27^{\circ} \mathrm{C}$, umidade relativa de $64 \%$ e ausência de chuvas (Instituto..., 2012), apresentando baixas capturas nas outras avaliações. Provavelmente, esse atrativo não necessita de umidade para ativar os ingredientes na captura das moscas.

Já no vinagre tinto de uva não houve praticamente aumentos significativos nas capturas das moscas quanto aos períodos de avaliação, ou seja, esse atrativo não foi influenciado pelos fatores climáticos.

Tabela 5 - Número médio de adultos de Anastrepha spp. capturados em atrativos alimentares alternativos à proteína hidrolisada de milho nas seis avaliações de campo em um pomar de goiaba no Município do Crato, CE.

\begin{tabular}{|c|c|c|c|c|c|c|}
\hline \multirow{2}{*}{ Tratamentos } & \multicolumn{6}{|c|}{ Avaliações } \\
\hline & $1^{\mathrm{a}}(20 / 1 / 2010)$ & $2^{\mathrm{a}}(27 / 1 / 2010)$ & $3^{\mathrm{a}}(2 / 2 / 2010)$ & $4^{\mathrm{a}}(9 / 2 / 2010)$ & $5^{\mathrm{a}}(16 / 2 / 2010)$ & $6^{\mathrm{a}}(24 / 2 / 2010)$ \\
\hline Proteína hidrolisada & $37,00 \mathrm{ab}$ & $37,75 \mathrm{ab}$ & $69,25 \mathrm{a}$ & $46,25 \mathrm{a}$ & $122,75 \mathrm{a}$ & $134,50 \mathrm{a}$ \\
\hline Caldo de cana & $4,50 \mathrm{~cd}$ & 7,75 bc & $4,50 \mathrm{~b}$ & $2,25 \mathrm{~d}$ & $6,5 c$ & $2,25 \mathrm{c}$ \\
\hline Fermento de pão & $1,75 \mathrm{~d}$ & $4,25 \mathrm{bc}$ & $9,75 \mathrm{~b}$ & $3,00 \mathrm{~cd}$ & $2,25 \mathrm{c}$ & $3,50 \mathrm{c}$ \\
\hline Vinagre tinto de uva & $1,25 \mathrm{~d}$ & $2,00 \mathrm{c}$ & $1,25 \mathrm{~b}$ & $1,25 \mathrm{~d}$ & $1,5 \mathrm{c}$ & $1,25 c$ \\
\hline Suco de goiaba & $43,5 \mathrm{a}$ & $79,25 \mathrm{a}$ & $64,75 \mathrm{a}$ & $33,25 \mathrm{ab}$ & $56,25 \mathrm{~b}$ & $55,75 \mathrm{~b}$ \\
\hline Açúcar mascavo & $18,00 \mathrm{bc}$ & $34,00 \mathrm{ab}$ & $15,50 \mathrm{~b}$ & $8,00 \mathrm{~cd}$ & $8,50 \mathrm{c}$ & $5,00 \mathrm{c}$ \\
\hline Urina humana & $1,25 \mathrm{~d}$ & $3,00 \mathrm{c}$ & $4,25 \mathrm{~b}$ & $4,50 \mathrm{~cd}$ & $13,00 \mathrm{bc}$ & $8,25 c$ \\
\hline Açúcar cristal & $2,50 \mathrm{~d}$ & $17,75 \mathrm{bc}$ & $23,00 \mathrm{ab}$ & $15,75 \mathrm{bc}$ & $10,25 \mathrm{c}$ & $4,00 \mathrm{c}$ \\
\hline Total & 110 & 186 & 192 & 114 & 221 & 214 \\
\hline C.V. & 22,47 & 31,17 & 30,16 & 22,47 & 29,04 & 30,91 \\
\hline
\end{tabular}

${ }^{2}$ Médias seguidas de mesma letra na coluna não diferem significativamente entre si pelo teste de Tukey a 5\% de probabilidade. 
Tabela 6 - Número médio de adultos de Ceratitis capitata capturados em atrativos alternativos à proteína hidrolisada de milho nas seis avaliações de campo em um pomar de goiaba no Município do Crato, CE.

\begin{tabular}{lcccccc}
\hline \multirow{2}{*}{ Tratamentos } & \multicolumn{6}{c}{ Avaliações } \\
\cline { 2 - 7 } & $1^{\mathrm{a}}(20 / 1 / 2010)$ & $2^{\mathrm{a}}(27 / 1 / 2010)$ & $3^{\mathrm{a}}(2 / 2 / 2010)$ & $4^{\mathrm{a}}(9 / 2 / 2010)$ & $5^{\mathrm{a}}(16 / 2 / 2010)$ & $6^{\mathrm{a}}(24 / 2 / 2010)$ \\
\hline Proteína hidrolisada & $2,75 \mathrm{ab}$ & $3,00 \mathrm{a}$ & $12,00 \mathrm{a}$ & $6,00 \mathrm{a}$ & $9,25 \mathrm{a}$ & $7,50 \mathrm{a}$ \\
Caldo de cana & $0,25 \mathrm{~cd}$ & $0,00 \mathrm{~b}$ & $0,00 \mathrm{~b}$ & $0,25 \mathrm{bc}$ & $0,00 \mathrm{c}$ & $0,00 \mathrm{~b}$ \\
Fermento de pão & $0,00 \mathrm{~d}$ & $0,25 \mathrm{~b}$ & $1,75 \mathrm{ab}$ & $0,25 \mathrm{bc}$ & $0,00 \mathrm{c}$ & $0,50 \mathrm{~b}$ \\
Vinagre tinto de uva & $0,75 \mathrm{bcd}$ & $0,50 \mathrm{~b}$ & $0,25 \mathrm{~b}$ & $0,00 \mathrm{c}$ & $0,00 \mathrm{c}$ & $0,00 \mathrm{~b}$ \\
Suco de goiaba & $2,00 \mathrm{abc}$ & $1,75 \mathrm{a}$ & $0,75 \mathrm{~b}$ & $1,25 \mathrm{~b}$ & $0,50 \mathrm{bc}$ & $0,50 \mathrm{~b}$ \\
Açúcar mascavo & $0,50 \mathrm{bcd}$ & $0,00 \mathrm{~b}$ & $0,75 \mathrm{~b}$ & $0,50 \mathrm{bc}$ & $0,00 \mathrm{c}$ & $0,75 \mathrm{~b}$ \\
Urina humana & $7,75 \mathrm{a}$ & $1,50 \mathrm{a}$ & $1,75 \mathrm{ab}$ & $1,50 \mathrm{~b}$ & $1,50 \mathrm{~b}$ & $0,25 \mathrm{~b}$ \\
Açúcar cristal & $0,00 \mathrm{~d}$ & $0,00 \mathrm{~b}$ & $0,25 \mathrm{~b}$ & $0,25 \mathrm{bc}$ & $0,00 \mathrm{c}$ & $0,00 \mathrm{~b}$ \\
\hline Total & 14 & 7 & 17 & 10 & 11 & 9 \\
\hline C.V. & 29,15 & 18,18 & 36,56 & 24,90 & 26,17 & 22,60 \\
\hline
\end{tabular}

${ }^{1}$ Dados transformados em $\sqrt{ } \mathrm{x}+1$.

${ }^{2}$ Médias seguidas de mesma letra na coluna não diferem significativamente entre si pelo teste de Tukey a 5\% de probabilidade.

Portanto, diferente das armadilhas, percebeuse que nos atrativos alimentares não houve um padrão de captura com relação aos períodos de avaliação no campo, certamente devido à variação na composição química e/ou física dos diferentes atrativos e à presença de diferentes espécies de Anastrepha, uma vez que AzEvedo et al., (2010) constataram nessa área seis diferentes espécies, com dominância de $A$. zenildae e A. obliqua. Essa variabilidade de diferentes atrativos alimentares manteve uma captura constante ao longo das seis avaliações no campo devido a preferência de cada uma das espécies pelos atrativos com populações sempre acima de 100 indivíduos (Tabela 5). Comportamento contrário foi observado com as armadilhas onde a população decresceu ao longo dessas avaliações (Tabela 2), provavelmente devido ao fato de existir apenas um tipo de atrativo alimentar que foi a proteína hidrolisada de milho.

A maior captura de C. capitata nos atrativos alimentares testados foi observada na proteína hidrolisada, com maior população capturada no dia 02/02/2010, obtendo-se em média 12 adultos (Tabela 6). Nessa data não choveu, de modo que temperatura alcançou os $27^{\circ} \mathrm{C}$ e a umidade ficou em torno de 64\% (InstiTuto..., 2012). Portanto, um ambiente quente é seco e provavelmente propício para essa espécie.

Depois desse atrativo, apenas a urina humana capturou uma população considerável no dia 20 de janeiro de 2010, da ordem de 7,75 moscas, mantendo-se abaixo de 2 moscas da segunda até a última avaliação. A alta temperatura de $27^{\circ} \mathrm{C}$, a baixa umidade de $67 \%$ e ausência de chuva (InstituTo..., 2012) favoreceram esse atrativo, pois houve uma maior concentração de amônia devido a evaporação da água nessas condições.
O suco de goiaba capturou uma baixa população na primeira e segunda avaliação, obtendo-se 2 e 1,75 adultos, respectivamente, no entanto, foi maior do que os demais atrativos que obtiveram baixíssimas capturas e alguns não chegaram se quer a capturar moscas. Nesses períodos de avaliação havia uma maior disponibilidade de frutos que permitiu essas capturas, mas com a colheita dos frutos houve redução e, ainda, ausência das moscas no campo.

Da mesma forma do que foi observado nas armadilhas que não chegaram a capturar 10 adultos nos diferentes períodos de avaliação (Tabela 3), o mesmo foi verificado na maioria dos atrativos, comprovando a baixa densidade populacional dessa espécie de moscas-das-frutas no pomar de goiaba. Além de a preferência alimentar por culturas introduzidas como o café, outro fator que pode ter contribuído para a reduzida captura dessa praga pode ter sido a competição interespecífica com as espécies de Anastrepha, pois nessa pesquisa capturaram-se 4.144 adultos, porém não foram identificadas em nível de espécie.

\section{CONCLUSÕES}

1. A garrafa PET apresenta eficácia semelhante e por vezes superior a McPhail, com maior captura de moscas-da-fruta no período de maior disponibilidade de frutos.

2. O frasco de vinagre demonstra uma eficácia satisfatória na captura de moscas-da-fruta.

3. O suco de goiaba pode ser utilizado na captura de moscas-da-fruta em substituição a proteína hidrolisada de milho.

4. O fermento biológico e o vinagre tinto de uva são ineficazes na captura de moscas-da-fruta. 


\section{REFERÊNCIAS}

AGUIAR-MENEZES, E.L.; SOUZA, J.F.; SOUZA, S.A.S.; LEAL, M.R.; COSTA, J.R.; MENEZES, E.B. Armadilha PET para captura de adultos de moscas-das-frutas em pomares comerciais e domésticos. Seropédica, RJ: Embrapa Agrobiologia, 2006. 8p. (Circular Técnica, 16).

ALUJA, M.; PIÑERO, J. Testing human urine as a low-tech bait for Anastrepha spp. (Diptera: Tephritidae) in small guava, mango, sapodilla and grapefruit orchards. Florida Entomologist, v.87, n.1, p.41-50, 2004.

ARAUJO, E.L.; ZUCCHI, R.A. Moscas-das-frutas (Diptera:Tephritidae) em goiaba (Psidium guajava), em Mossoró RN. Arquivos do Instituto Biológico, São Paulo, v.70, n.1, p.73-77, 2003.

AZEVEDO, F.R.; GUIMARÃES, J.A.; SIMPLÍCIO, A.A.F.; SANTOS, H.R. Análise faunística e flutuação populacional de moscas-dasfrutas (diptera: tephritidae) em pomares comerciais de goiaba na região do cariri cearense. Arquivos do Instituto Biológico, São Paulo, v.77, n.1, p.33-41, 2010.

BARROS, M.D.; AMARAL, P.M.; MALAVASI, A. Comparison of glass and plastic McPhail traps in the capture of the South American fruit fly Anastrepha fraterculus (Diptera: Tephritidae) in Brazil. Florida Entomologist, v.74, n.3, p.467-468, 1991.

BRESSAN, S.; TELES, M.C. Lista de hospedeiros e índices de infestação de algumas espécies do gênero Anastrepha Schiner, 1868 (Diptera: Tephritidae) na região de Ribeirão Preto-SP. Anais da Sociedade Entomológica do Brasil, v.20, n.1, p.5-15, 1991.

CAMARGO, M.A.; GUERREIRO, J.C. Avaliação de atrativos alimentares para monitoramento da mosca-das-frutas em pomar de goiabeira (Psidium guajava). Revista Científica Eletrônica de Agronomia, n.11, 2007. Disponivel em: <http://www.revista.inf.br/agro11/artigos/anovi-edic11-art02.pdf> Acesso em: 30 mai. 2012.

COSTA, N.P.; MEDEIROS, J.G.F.; ARAÚJO, R.C.; ARAÚJO, E.L. Substâncias atrativas usadas na captura de espécies de moscas-das-frutas (Diptera: Tephritidae) em goiabeiras no município de bananeiras, PB. In: CONGRESSO BRASILEIRO DE FRUTICULTURA, 20., 2008, Vitória, ES. Resumos. CD_ROM.

GARCIA, F.M.; CAMPOS, J.V.; CORSEUIL, E. Flutuação populacional de Anastrepha fraterculus (Wiedemann, 1830) (Diptera: Tephritidae) na Região Oeste de Santa Catarina, Brasil. Revista Brasileira de Entomologia, v.47, p.415-420, 2003

HEATH, R.R.; EPSKY, N.D.; GUZMÁN, A.; DUEBEN, B.D.; MANUKIAN, A.; MEYER, W.L. Development of a dry plastic insect trap with food-based synthetic attractant for the Mediterranean and Mexican fruit flies
(Diptera: Tephritidae). Journal Economic of Entomology, v.88, p.1307-1315, 1995.

HEDSTROM, I.; JIRÓN, L.F. Evaluación de campo de substancias atrayentes en la captura de Anastrepha spp. (Diptera, Tephritidae), plaga de frutales en América Tropical. I. Melaza y tórula. Revista Brasileira de Entomologia, v.29, n.3/4, p.515-520, 1985.

INSTITUTO AGROPOLOS DO CEARÁ. Cultivo da goiaba no Cariri. 2012. Disponível em: <http:www.institutosagropolos.org.br>. Acesso em: 30 mai. 2012.

INSTITUTO NACIONAL DE METEOROLOGIA (Brasil). Dados meteorológicos do Cariri 2009. Disponível em: <http://www.agritempo.gov.br/agroclima/pesquisa>. Acesso em: 2 Jul. 2012.

LEMOS, R.N.S.; SILVA, C.M.C.; ARAÚJO, J.R.G.; COSTA, L.J.M.P.; SALLES, J.R.J. Eficiência de substâncias na captura de moscas das frutas (Díptera: Tephritidae) emgoiabeiras no município de Itapecuru-Mirim (MA). Revista Brasileira de Fruticultura, v.24, n.3, p.687-689, 2002.

LORENZATO, D. Eficiência de frascos e atrativos no monitoramento e combate de moscas das frutas do gênero Anastrepha e Ceratitis capitata. Agronomia Sulriograndense, v.20, n.2, p.45-62, 1984.

MANICA, I.; ICUMA, I.M.; JUNQUEIRA, N.T.V.; SALVADOR, J.O.; MOREIRA, A.; MALAVOLTA, E. Fruticultura Tropical 6. Goiaba. Porto Alegre: Cinco Continentes, 2000. 374p.

MONTES, S.M.N.; RAGA, A. Eficácia de atrativos para monitoramento de Ceratitis capitata (Diptera: Tephritidae) em pomar de citros. Arquivos do Instituto Biológico, São Paulo, v.73, n.3, p.317-323, 2006.

NASCIMENTO, A.S.; CARVALHO, R.S.; MALAVASI, A. Monitoramento populacional. In: MALAVASI, A.; ZUCCHI, R. A. (Ed.). Moscas-das-frutas de importância econômica no Brasil: conhecimento básico e aplicado. Ribeirão Preto: Holos Ed., 2000. cap.13, p.109-112.

PIÑERO, J.; ALUJA, M.; EQUIHUA, M.; OJEDA, M.M. Feeding history, age and sex influence the response of four economically important Anastrepha species (Diptera: Tephritidae) to human urine and hydrolyzed protein. Folia Entomologica Mexicana, v.41, p.283-298, 2002.

PIÑERO, J.; ALUJA, M.; VÁZQUEZ, A.; EQUIHUA, M.; VARÓN, J. Human urine and chicken feces as fruit fly (Diptera: Tephritidae) attractants for resource-poor fruit growers. Journal of Economic Entomology, v.96, n.2, p.334-340, 2003.

SALLES, L.A.B. Efeito do envelhecimento e da decomposição do atrativo na captura de adultos de Anastrepha fraterculus (Wied.) (Diptera: Tephritidae). Revista Brasileira de Agrociência, v.5, n.2, p.147-148, 1999. 
SALLES, F.J.M.; GONÇALVES, N.G.G. Moscas-das-frutas nos estados brasileiros - Ceará. In: MALAVASI, A.; ZUCCHI, R.A. (Ed.). Moscas-das-frutas de importância econômica no Brasil: conhecimento básico e aplicado. Ribeirão Preto: Holos Ed., 2000. cap. 30, p. 217-222.

THOMAS, D.B.; HOLLER, T.C.; HEATH, R.R.; SALINAS, E.J.; MOSES, A.L. Trap-lure combinations for surveillance of Anastrepha fruit flies (Diptera: Tephritidae). Florida Entomologist, v.84, n.3, p.344-351, 2001.

ZANCHETA, P.G. Recuperação e tratamento da urina humana para uso agrícola. 2007. 83f. Dissertação (Mes- trado em Engenharia Ambiental) - Centro Tecnológico, Universidade Federal do Espírito Santo,Vitória, 2007.

ZUCCHI, R.A. Mosca-do-mediterrâneo, Ceratitis capitata (Diptera: Tephritidae). In: VILELA, E.F.; ZUCCHI, R.A.; CANTOR, F. (Ed.). Histórico e impacto das pragas introduzidas no Brasil. Ribeirão Preto: Holos Ed., 2001. cap. 1, p.15-22.

Recebido em 19/10/10

Aceito em 5/7/12 